\title{
Preliminary Study on the Performance of a Redox Capacitor with the use of Ionic Liquid-based Gel Polymer Electrolyte and Polypyrrole Electrodes
}

KAPURALAGE WATHSALA PRASADINI ( $\nabla$ w.prasadi56@gmail.com )

ITI: Industrial Technology Institute https://orcid.org/0000-0002-9587-248X

Kumudu Sandhya Perera

Wayamba University of Sri Lanka

Kamal Pushpakumara Vidanapathirana

Wayamba University of Sri Lanka

\section{Research Article}

Keywords: ionic liquid (IL) based gel polymer electrolyte (GPE), conducting polymer, redox capacitors, single electrode specific capacitance (CSC)

Posted Date: February 19th, 2021

DOI: https://doi.org/10.21203/rs.3.rs-218412/v1

License: (c) (1) This work is licensed under a Creative Commons Attribution 4.0 International License. Read Full License 


\title{
Preliminary study on the performance of a redox capacitor with the use of ionic liquid-based gel polymer
}

\section{electrolyte and polypyrrole electrodes}

Kapuralage W. Prasadini* , Kumudu S. Perera, Kamal P. Vidanapathirana

Polymer Electronics Research Group, Faculty of Applied Sciences, Wayamba University of Sri Lanka,

Kuliyapitiya, Sri Lanka

*w.prasadini@wyb.ac.lk

\begin{abstract}
Redox capacitor, which is one type of supercapacitor, has been attracted tremendously as they show a satisfactory specific capacitance, good cycle ability, and good stability. The present study reveals a redox capacitor fabricated with an ionic liquid (IL) based gel polymer electrolyte (GPE). Electrodes of the redox capacitor were fabricated with the conducting polymer, polypyrrole (PPy). The composition of the GPE was polyvinylidenefluoride-co-hexafluoropropylene (PVdF-co-HFP) : 1-ethyl-3-methylimidazolium trifluoromethanesulfonate (1E3MITF) : ZnTF. Characterization of redox capacitor was done by electrochemical impedance spectroscopy (EIS), cyclic voltammetry (CV), and galvanostatic charge-discharge (GCD) tests. The relaxation time constant $(\tau 0)$ of the redox capacitor is about $31.57 \mathrm{~s}$ implying somewhat fast redox reactions. Initial single electrode specific capacitance (CSC) was $150.16 \mathrm{Fg}-1$ and at the 500th cycle, it was $40.03 \mathrm{Fg}-1$. The decrease of the CSC may be due to the formation of the passivation layer at the GPE / electrode interface resulting in degradation upon cycling. The GCD test resulted $48.40 \mathrm{Fg}-1$ of initial single electrode specific discharge capacitance (Csd) value. Upon 1000 cycles, it was reached $22.25 \mathrm{Fg}-1$. The decrease of Csd may be due to the degradation of the electrode and the IL-based GPE upon prolonged cycling.
\end{abstract}

Keywords: ionic liquid (IL) based gel polymer electrolyte (GPE), conducting polymer, redox capacitors, single electrode specific capacitance $\left(\mathrm{C}_{\mathrm{SC}}\right)$ 


\section{Introduction}

Increasing demand for power and energy sources lead to creating a new challenge of design and fabrication of low cost, eco-friendly, and more efficient energy storage devices. In this context, supercapacitors (SCs) become attractive candidates for energy storage devices due to their higher power density when compare with the rechargeable cells and higher energy densities than conventional capacitors [1]. Therefore, SCs have been adapted for applications that require a short period for the charging process such as in automobiles, forklifts, and tramways [2], [3].

Generally, SCs are classified as electrochemical double-layer capacitors (EDLCs) and redox capacitors based on their charge storage mechanism. EDLCs store charges through the electrostatic interaction of ions in the electrolyte with the active electrode material whereas in redox capacitors faradic redox reactions are taken place [4]. Carbon-based electrodes are used for EDLCs and conducting polymer or transition metal electrodes are used for redox capacitors. Moreover, redox capacitors have become prominent due to their easy and less complex fabrication techniques, satisfactory specific capacity values as well as good flexibility of conducting polymers [5].

Besides, most of the studies on redox capacitors have been carried out by using liquid electrolytes [6], [7], [8]. However, due to some adverse effects such as leakage, toxic and volatile issues, gel polymer electrolytes (GPEs) have received great attention later as a suitable substitute for liquid electrolytes. Generally, GPEs are prepared by trapping an ionic salt that is dissolved with polar solvent in a polymeric network. Although these electrolytes have wide electrochemical potential windows, good conductivities, and mechanical stability still are suffering from poor electrochemical and thermal properties [9]. Thus, recently room temperature ionic liquids (RTILs) have been identified as one of the best alternatives for organic solvents due to their unique properties such as non-volatility, good thermal and chemical properties, wider potential windows, etc. [10], [11]. In literature, some papers have mentioned the importance of ILs in supercapacitor applications such as long term safety of the devices, fast ionic transport properties, wide operating temperature range of the device, proper electrodeelectrolyte contacts, enhance the capacitance performance of the device, improve the energy density without sacrificing cycle life and safety, fast charge-discharge conditions [12], [13], [14], [15]. Moreover, many studies have reported that the use of IL-based GPEs in lithium (Li) rechargeable cells and supercapacitors [16], [17]. However, due to the toxicity of Li metal, non-Li-based devices fabricated with materials like sodium (Na), zinc $(\mathrm{Zn})$, magnesium $(\mathrm{Mg})$, and copper $(\mathrm{Cu})$ are prominently used in the present world.

The present study reports the fabrication and characterization of a redox capacitor with conducting polymer, polypyrrole (PPy) based electrodes, and an IL-based GPE prepared by using 1-ethyl-3-methylimidazolium trifluoromethanesulfonate (1E3MITF), zinc trifluoromethanesulfonate $(\mathrm{Zn}(\mathrm{CF} 3 \mathrm{SO} 3) 2, \mathrm{ZnTF})$, and polyvinylidene fluoride-co-hexafluoropropylene (PVdF-co-HFP). For the characterization of the fabricated redox capacitor, electrochemical impedance spectroscopy (EIS) technique, cyclic voltammetry (CV) test, and galvanostatic charge-discharge (GCD) test were performed at room temperature.

\section{Experimental}

\subsection{Preparation of IL-based GPE}


PVdF-co-HFP (average M.W. 400,000 gmol $\left.^{-1}\right)$, $1 \mathrm{E} 3 \mathrm{MITF}(98 \%)$ and $\mathrm{Zn}\left(\mathrm{CF}_{3} \mathrm{SO}_{3}\right)_{2} \quad(\mathrm{ZnTF}$, 98\%) were purchased from Sigma Aldrich and used without any further purification. The composition of GPE was 1 PVdFco-HFP : 1 1E3MITF : 3 ZnTF by weight basis. Traditional solvent casting technique was used to prepare the IL-based GPE. In the solvent casting technique, a polymer is dissolved in a common solvent and when a polymer is completely dissolved in the solvent, appropriate amounts of salt and IL are added. Then, the mixture is stirred for sufficient time ensuring the complexation of salt and IL in the polymer host. Then, the resulting viscous and homogeneous mixture is poured into a glass petri dish for film formation via slow evaporation of the solvent. Thereby it is possible to obtain a bubble-free, thin and freestanding electrolyte film.

In this study, the Required amount of PVdF-co-HFP was completely dissolved in acetone by using a magnetic stirrer at room temperature. Then, the required amounts of ZnTF and 1E3MITF were added to the resulting mixture and it was again magnetically stirred overnight. The resulting homogeneous solution was poured into a glass petri dish and allowed to evaporate acetone at room temperature to obtain a freestanding film.

\subsection{Preparation of conducting polymer electrodes}

Electrodes of redox capacitor were fabricated by using the conducting polymer, polypyrrole (PPy). First, pyrrole (Aldrich, 98\%) was distilled and stored in dark before use. Electrochemical polymerization was done in the presence of $\mathrm{ZnTF}$ which was dissolved in propylene carbonate (PC) on fluorine-doped tin oxide (FTO) glass plates using a computer-controlled Metrohm Autolab M101 potentiostat. A three-electrode setup was used for electrochemical polymerization consisted of a working electrode (FTO), reference electrode $(\mathrm{Ag} / \mathrm{AgCl})$, and a counter electrode $(\mathrm{Pt})$. The thickness of PPy film was $2 \mu \mathrm{m}$.

\subsection{Fabrication of redox capacitor}

Sandwich type symmetric capacitors were fabricated using PPy electrodes. Prepared PPy based electrodes were dried at about $60{ }^{\circ} \mathrm{C}$ in an oven. The square-shaped electrolyte was cut and it was placed in between two PPy based electrodes and sealed properly. The area of the electrolyte was $1 \mathrm{~cm}^{2}$.

\subsection{Electrochemical impedance spectroscopy (EIS) measurements}

Impedance measurements of the redox capacitor were gathered using a Metrohm Autolab M101 impedance analyzer in the frequency range from $0.001 \mathrm{~Hz}$ to $400 \mathrm{kHz}$. A three-electrode setup was used to perform the EIS test. One electrode of the redox capacitor was served as the working electrode and the other electrode was used as both counter and reference electrodes together.

\subsection{Cyclic voltammetry (CV) test}

Cyclic voltammetry (CV) studies were carried out for the redox capacitor within various potential windows and at different scan rates by using a computer-controlled Metrohm Autolab M101 potentiostat. A three-electrode setup was used to perform the CV test as described in the EIS technique.

\subsection{Galvanostatic charge-discharge (GCD) test}

Galvanostatic charge-discharge (GCD) test was carried out using a computer-controlled Metrohm Autolab M101 potentiostat and using a three-electrode setup as same as the EIS measurement and CV test. For the GCD test, a constant current of $230 \mu \mathrm{A}$ was used. 


\section{Results and discussion}

\subsection{Electrochemical impedance spectroscopy (EIS) measurements}

Fig. 1 illustrates resulted Nyquist plot of the fabricated redox capacitor PPy: ZnTF/ 1E3MITF: ZnTF: PVdF-coHFP/ PPy: ZnTF within the frequency range from $0.001 \mathrm{~Hz}$ to $400 \mathrm{kHz}$.

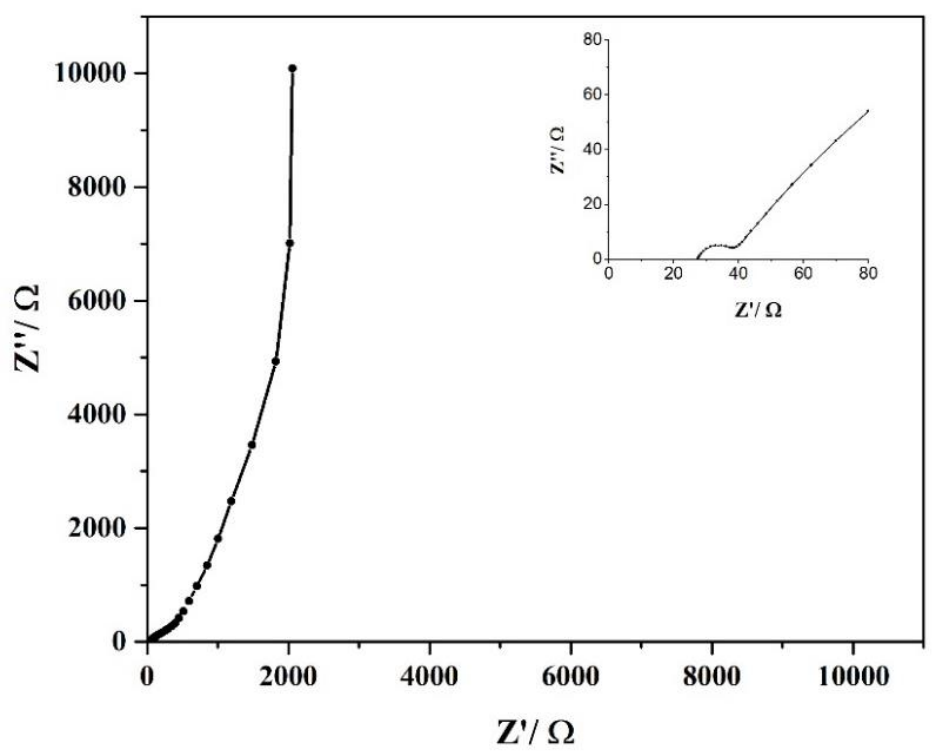

Fig.1: The Nyquist plot of the redox capacitor PPy: ZnTF/ 1E3MITF: ZnTF: PVdF-co-HFP/ PPy: ZnTF in the frequency range $0.001 \mathrm{~Hz}$ to $400 \mathrm{kHz}$

Generally, the Nyquist plot of a supercapacitor consists of two semi-circles at high and mid-frequency regions and spikes with two inclinations at low-frequency range. There, bulk electrolyte resistance (Rb) which corresponds to the internal resistance is represented by the first semi-circle. The charge transfer resistance at the electrode/ electrolyte interface is denoted by the mid-frequency semi-circle. Spikes with two inclinations at a low-frequency range represent the diffusion and the capacitive behavior [18]. Nyquist plot in Fig. 1 does not have a high frequency semi-circle probably due to the unavailability of the required high frequency [11]. Thus, the bulk electrolyte resistance $\left(R_{b}\right)$ was taken at the first intercept of the real axis $\left(Z^{\prime}\right)$ of the Nyquist plot and the intercept is clearly shown in the insert of Fig. 1. According to the obtained data, the bulk electrolyte resistance $\left(\mathrm{R}_{\mathrm{b}}\right)$ is low (around $25 \Omega$ ) and this confirms ionic conductivity of the prepared GPE was high. In addition, a spike with two inclinations can be observed as per Fig.1 and the lowest frequency spike is nearly parallel to the imaginary axis $\left(Z^{\prime \prime}\right)$ confirming the capacitive behavior of the fabricated redox capacitor [19]. The single electrode capacitance $\left(\mathrm{C}_{\mathrm{SC}}\right)$ based on impedance data is about $31.55 \mathrm{Fg}^{-1}$ according to the equation,

$\mathrm{C}_{\mathrm{SC}}=1 /\left(2 \pi \mathrm{fZ} \mathrm{Z}^{\prime \prime} \mathrm{m}\right)$

where, $\mathrm{f}$ is the lowest frequency value, $\mathrm{Z}$ " is the imaginary value of impedance at frequency $\mathrm{f}$ and $\mathrm{m}$ is the single electrode mass.

Fig.2 (a) and (b) represent the bode plots resulted from the EIS technique in the frequency range from $0.001 \mathrm{~Hz}$ to $400 \mathrm{kHz}$. The real part of the capacitance, $\mathrm{C}^{\prime}$ is about $30.28 \mathrm{Fg}^{-1}$ and it is nearly same as the $\mathrm{C}_{\mathrm{SC}}$ resulted from EIS data. 
As can be seen in the figure (a), there is a drastic drop of $\mathrm{C}^{\prime}$ with increase of frequency. Besides, it reaches near to zero upon further increase of the frequency. This reveals capacitive behavior is dominant at lower frequencies and resistive properties override capacitive properties at higher frequencies [20].
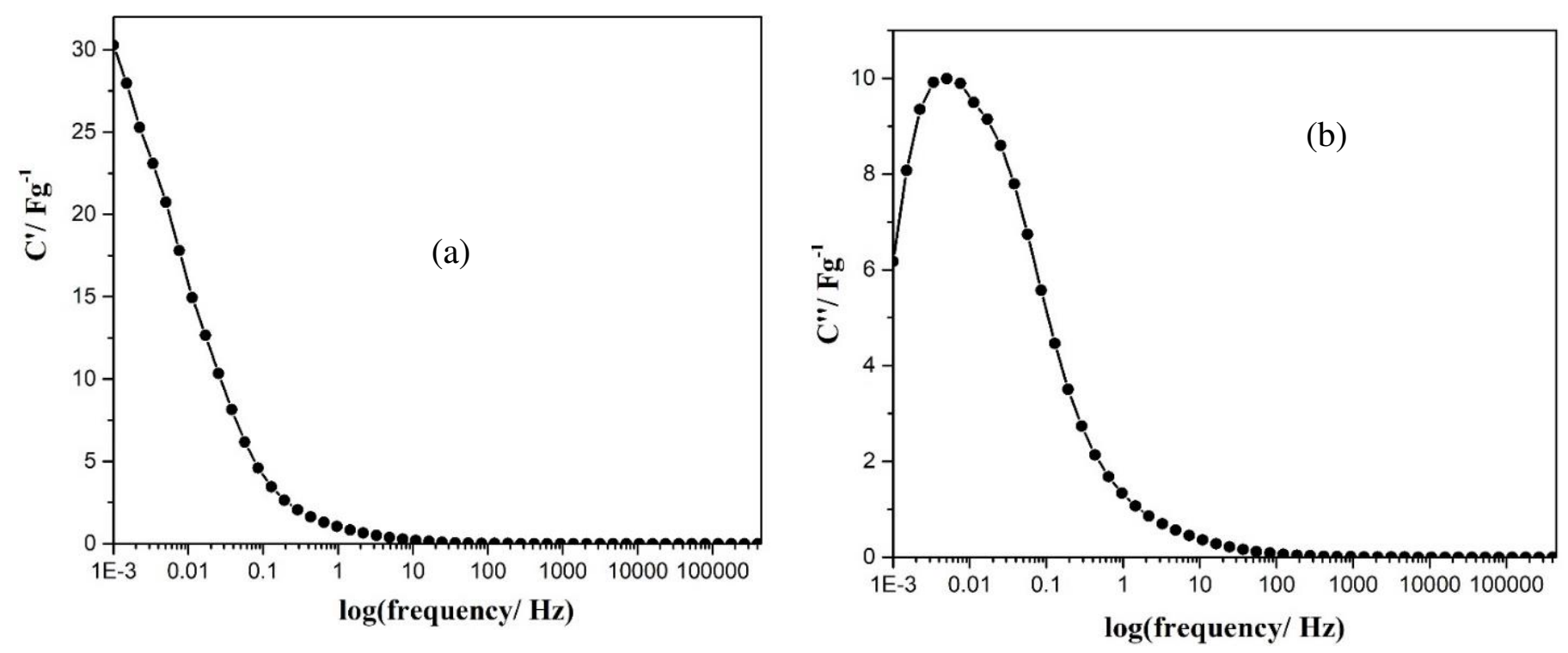

Fig. 2: Bode plots of the redox capacitor PPy: ZnTF/ 1E3MITF: ZnTF: PVdF-co-HFP/ PPy: ZnTF in the frequency range $0.001 \mathrm{~Hz}$ to $400 \mathrm{kHz}$

Moreover, the relaxation time constant $\tau_{0}$, is $31.57 \mathrm{~s}$ which was calculated by the equation

$$
\tau_{0}=1 /\left(2 \pi f_{0}\right)
$$

where $\mathrm{f}_{0}$ is the frequency at the maximum $\mathrm{C}^{\prime \prime}$. This hints that the fabricated redox capacitor has quite fast redox reactions [21].

\subsection{Cyclic voltammetry (CV) measurements}

Fig. 3 shows the potential window variation of the fabricated redox capacitor at the scan rate of $10 \mathrm{mVs}^{-1}$.

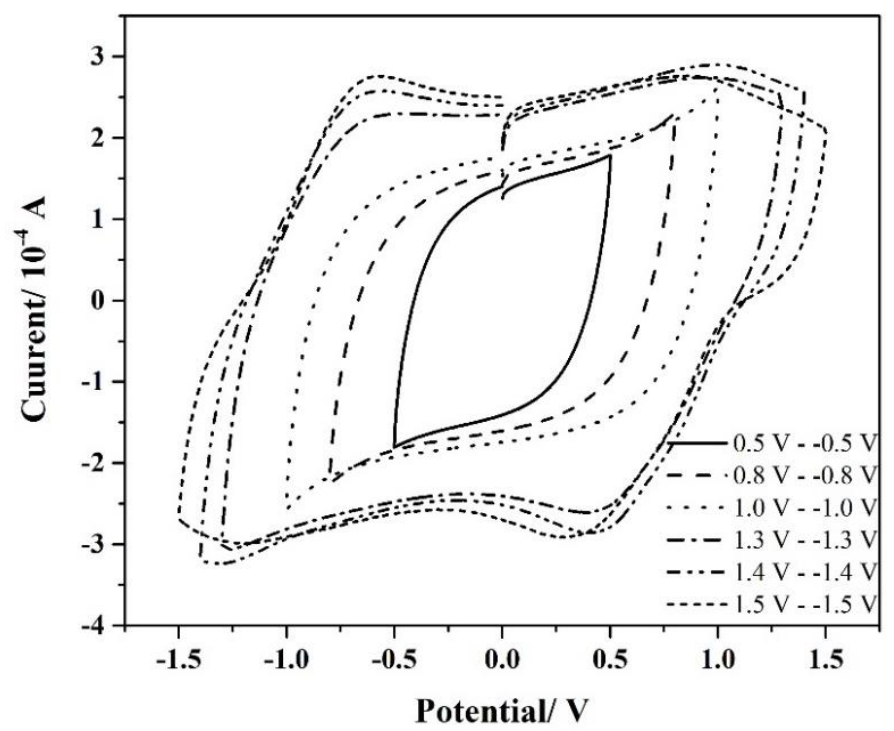


Fig.3: Cyclic voltammograms at different potential windows at the scan rate of $10 \mathrm{mVs}^{-1}$ for the redox capacitor PPy : ZnTF/ PVdF-co-HFP : 1E3MITF : ZnTF/ PPy : ZnTF

Within the narrow potential windows, no peaks can be observed and when the potential windows are increased, peaks can be observed. Generally, redox capacitors perform fast oxidation and reduction reactions and show redox peaks in the cyclic voltammograms [22]. The absence of such peaks at lower potential windows shows that the corresponding redox reactions are not taking place within these potential ranges. When the required potential windows are available, redox reactions are taking place and peaks are appearing in the cyclic voltammograms [23]. Moreover, there are two sets of redox peaks in Fig.3. One set of peaks may be due to the doping and de-doping of the PPy electrodes [24]. The other redox peaks due to the impurities present in the PPy electrode are getting active at a required potential. During charge cycle, cations in the GPE transfer to PPY electrode and opposite reaction takes place during discharge.

In addition, all cyclic voltammograms show near mirror-image symmetry of the current response and confirm the capacitive nature of the redox capacitor [6]. The best window was selected by considering the shape of the cyclic voltammograms and the single electrode specific capacitance $\left(\mathrm{C}_{\mathrm{SC}}\right)$ values calculated by the equation,

$\mathrm{C}_{\mathrm{SC}}=2 \int \mathrm{I}(\mathrm{dV}) /(\mathrm{m} \Delta \mathrm{v} \mathrm{S})$

where, $\int \mathrm{I}(\mathrm{dV})$ is the integrated area of cyclic voltammogram, $\mathrm{m}$ is the mass of a single electrode, $\Delta \mathrm{v}$ is the potential window and $\mathrm{S}$ is the scan rate.

Then, $-1.4 \mathrm{~V}$ to $1.4 \mathrm{~V}$ window was taken for continuous cycling because this window shows a high value for $\mathrm{C}_{\mathrm{SC}}$ and a better shape of the cyclic voltammogram.

Cyclic voltammograms were obtained for the potential window from $-1.4 \mathrm{~V}$ to $1.4 \mathrm{~V}$ at various scan rates and the corresponding $\mathrm{C}_{\mathrm{SC}}$ values are shown in Fig. 4 (a) and (b).
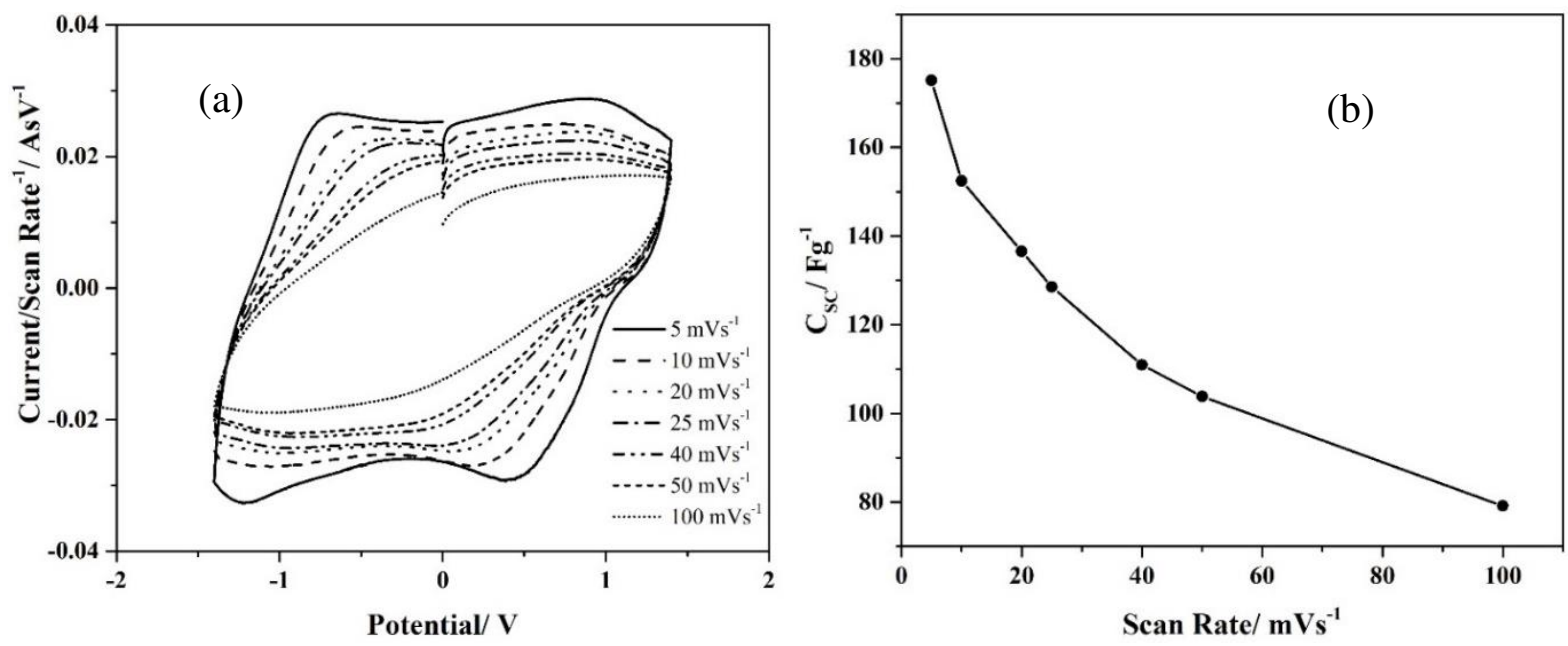

Fig. 4: (a) Resulted cyclic voltammograms at different scan rates (b) corresponding $\mathrm{C}_{\mathrm{SC}}$ values of the cyclic voltammograms at the window from $-1.4 \mathrm{~V}$ to $1.4 \mathrm{~V}$ for the redox capacitor PPy : ZnTF/ PVdF-co-HFP : 1E3MITF : ZnTF/ PPy : ZnTF

As same as Fig.3, near mirror-image symmetry can be observed in all cyclic voltammograms in Fig. 4 (a) confirming the capacitive behavior of the redox capacitor. According to Fig. 4(b), it is seen that Csc decreases with increasing the scan rate. This may associate with the occurrence of incomplete redox reactions which do 
not allow complete charge storage at high scan rates [9], [25]. The scan rate of $10 \mathrm{mVs}^{-1}$ was selected as the optimized scan rate for further studies.

Fig.5 (a) and (b) illustrate cyclic voltammograms and corresponding $\mathrm{C}_{\mathrm{SC}}$ values as a function of cycle number.
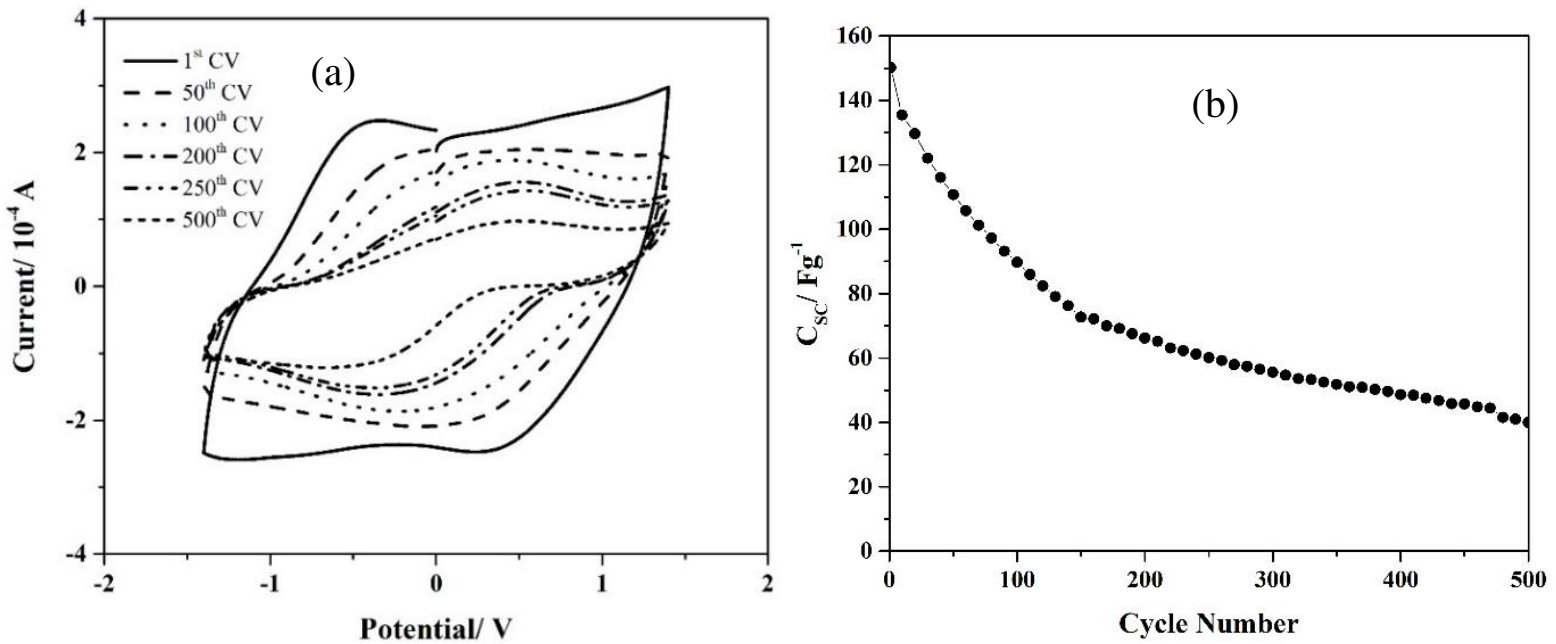

Fig. 5 (a) First, $50^{\text {th }}, 100^{\text {th }}, 200^{\text {th }}, 250^{\text {th }}$, and $500^{\text {th }}$ cyclic voltammograms (b) Variation of $\mathrm{C}_{S C}$ upon continuous cycling at the scan rate of $10 \mathrm{mVs}^{-1}$ and within the potential from $-1.4 \mathrm{~V}$ to $1.4 \mathrm{~V}$

As per Fig.5 (a), redox peaks can be observed clearly at the first cycle and when the number of cycles increases, the current of the redox peaks decreases. This may due to the degradation of the PPy based electrodes and the IL-based GPE upon continuous cycling. Moreover, according to Fig. 5 (b), the initial $\mathrm{C}_{\mathrm{SC}}$ value for the redox capacitor was $150.16 \mathrm{Fg}^{-1}$ and the $\mathrm{C}_{\mathrm{SC}}$ value is gradually decreasing to $40.03 \mathrm{Fg}^{-1}$ within 500 cycles. The decrease of $\mathrm{C}_{\mathrm{SC}}$ with the cycle number confirms the degradation of the electrolyte and the electrodes as well as the formation of the passivation layer at the electrode-electrolyte interface with continuous cycling [26].

Moreover, redox capacitors employ the Faradic process. They can store more energy than EDLCs because of the fast and reversible Faradic processes, in combination with the non-Faradic formation of the electric double-layer [27]. However, as compared with EDLCs, the redox capacitors have low cycling stability due to the Faradic reactions. Redox capacitors made from $\mathrm{RuO}_{2}$ electrodes show high performances though they are expensive materials. Thus, conducting polymers which can store energy via doping and de-doping of ions from the electrolyte have been widely used as electrode materials [28].

\subsection{Galvanostatic charge-discharge (GCD) measurements}

Some of the resulted galvanostatic charge-discharge (GCD) cycles and single electrode specific discharge capacitance $\left(\mathrm{C}_{\mathrm{sd}}\right)$ with the cycle number for the redox capacitor PPy : ZnTF/ PVdF-co-HFP : 1E3MITF : ZnTF/ PPy : ZnTF under a constant current of $230 \mu \mathrm{A}$ is shown in Fig.6 (a) and (b). The $\mathrm{C}_{\mathrm{sd}}$ calculated by the equation [29],

$$
\mathrm{C}_{\mathrm{sd}}=\frac{\mathrm{I}}{\mathrm{m}\left(\frac{\mathrm{dV}}{\mathrm{dt}}\right)}
$$


where $\mathrm{I}$ is the constant current, $\mathrm{dV} / \mathrm{dt}$ is the rate of drop of potential excluding IR drop during discharge and $\mathrm{m}$ is the mass of a single electrode.
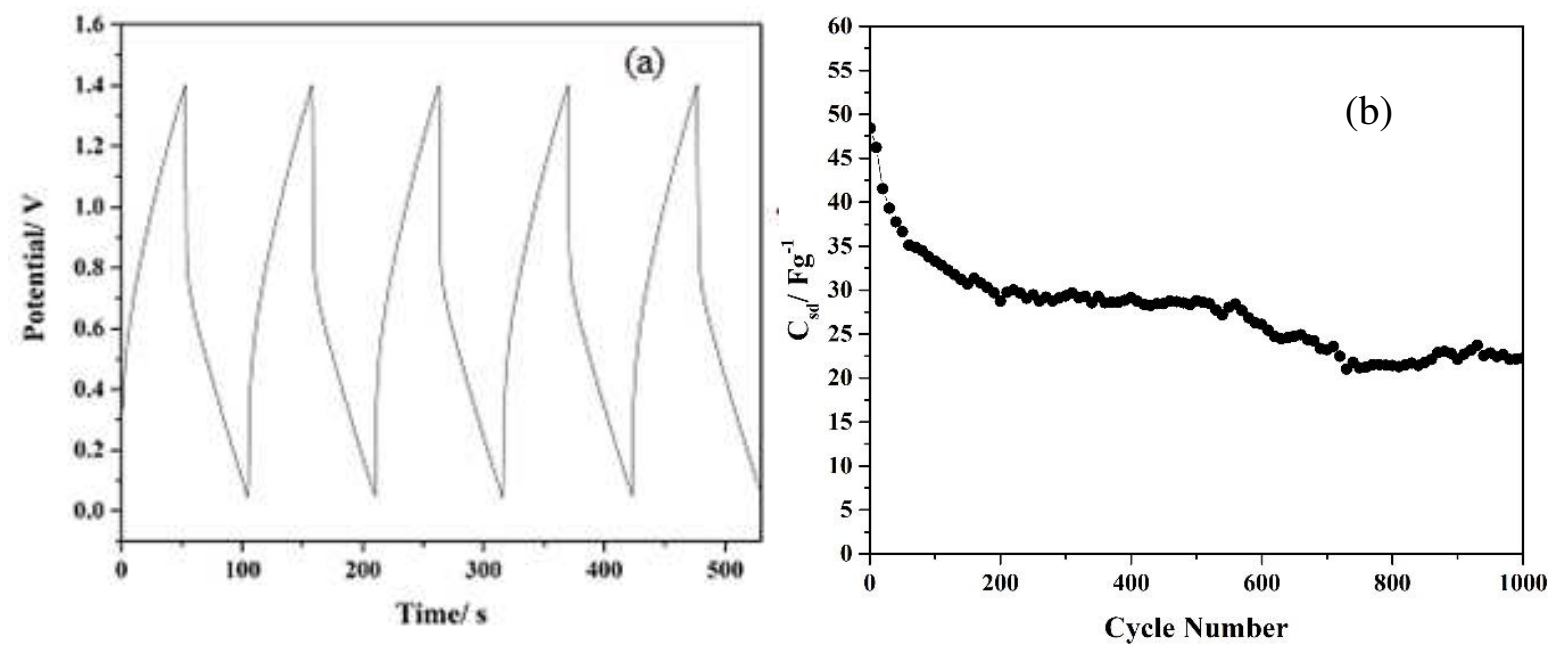

Fig. 6: (a) GCD cycles (b) variation of $\mathrm{C}_{\mathrm{sd}}$ with the cycle number for the redox capacitor PPy : ZnTF/ PVdF-coHFP : 1E3MITF : ZnTF/ PPy : ZnTF at constant current of $230 \mu \mathrm{A}$ within the potential $0.1 \mathrm{~V}$ to $1.4 \mathrm{~V}$

The charge-discharge curve illustrated in Fig. 6 (a) showed slope variations of charge-discharge curves with respect to time-dependent potential (non-ideal triangular shape) due to redox processes [30], [19]. In the discharge curve, the sudden drop of the potential is due to the IR drop. The IR drop occurs due to the resistance offered by the supercapacitor. Hence, some of the potential is used up to overcome this resistance while the rest of the potential is used for the discharging process of the redox capacitor. In the present study, a high IR drop (about $0.6 \mathrm{~V}$ ) can be seen. That may be due to the high internal resistance of the redox capacitor [31]. The $\mathrm{C}_{\mathrm{sd}}$ at the first GCD cycle was $48.40 \mathrm{Fg}^{-1}$. It was decreased with the cycle number and for the first 200 cycles, the rate of decrease is high. After about 200 cycles, the decrease rate is smaller than the initial. This may be associated with improper contacts of the IL-based GPE and the electrodes soon after fabrication and with time, contacts become mature. At the $1000^{\text {th }}$ GCD cycle, $\mathrm{C}_{\mathrm{sd}}$ reached $22.25 \mathrm{Fg}^{-1}$. The decrease of the $\mathrm{C}_{\mathrm{sd}}$ value may be due to the degradation of the IL-based GPE and the PPy based electrodes [32]. In addition, the formation of the passivation layer may also lead to reduce the $\mathrm{C}_{\mathrm{sd}}$ of the redox capacitor [33].

\section{Conclusion}

The redox capacitor was fabricated using the IL-based GPE with the composition of 1 polyvinylidenefluorideco-hexafluoropropylene (PVdF-co-HFP) : 1 1-ethyl-3-methylimidazolium trifluoromethanesulfonate (1E3MITF) : 3 zinc trifluoromethanesulfonate (ZnTF). Electrodes of redox capacitor were fabricated by polymerizing the conducting polymer, pyrrole and the salt, ZnTF in propylene carbonate. The single electrode specific capacitance, $\mathrm{C}_{\mathrm{SC}}$ resulted from the Nyquist plot was $31.55 \mathrm{Fg}^{-1}$ and it was $30.28 \mathrm{Fg}^{-1}$ as per bode plot data. The relaxation time constant $\left(\tau_{0}\right)$ was about $31.57 \mathrm{~s}$ indicating somewhat faster rate of redox reactions. Cyclic voltammetry $(\mathrm{CV})$ test was performed for the potential window from $-1.4 \mathrm{~V}$ to $1.4 \mathrm{~V}$ and at the scan rate of $10 \mathrm{mVs}^{-1}$. Initial $\mathrm{C}_{\mathrm{SC}}$ value for the redox capacitor was $150.16 \mathrm{Fg}^{-1}$ and it is decreasing continuously during continuous cycling. It was reported $40.03 \mathrm{Fg}^{-1}$ of $\mathrm{C}_{\mathrm{SC}}$ value at the $500^{\text {th }}$ cycle. The decrease may be due to the 
formation of passivation layer at the electrolyte electrode interface and the degradation of electrode/ electrolyte interface upon cycling. Galvanostatic charge-discharge (GCD) test was done under a constant current of $230 \mu \mathrm{A}$ and within the potential from $0.1 \mathrm{~V}$ to $1.4 \mathrm{~V}$. It resulted $48.40 \mathrm{Fg}^{-1}$ of initial single electrode specific discharge capacitance $\left(\mathrm{C}_{\mathrm{sd}}\right)$ value. During 1000 cycles, it reached to $22.25 \mathrm{Fg}^{-1}$. This decrease may be associated with the degradation of electrode and electrolyte interface upon prolonged cycling.

\section{Acknowledgements}

Authors wish to acknowledge National Science Foundation Sri Lanka for the financial support under the grant, RG/2017/BS/02 and Wayamba University of Sri Lanka.

\section{References}

[1] E. Frackowiak and Q. Abbas, “Carbon / carbon supercapacitors,” J. Energy Chem., vol. 22, pp. 226$240,2013$.

[2] X. Peng, Q. Shuhai, and X. Changjum, “A New Supercapacitor and Li-ion Battery Hybrid System for Electric Vehicle in advisor,” J. Phys. Conf. Ser., vol. 806, p. 012015, 2017.

[3] G. Xiong, C. Meng, R. G. Reifenberger, and P. P. Irazoqui, "Special Issue GRAPHENE A Review of Graphene-Based Electrochemical Microsupercapacitors,” Electroanalysis, vol. 26, pp. 30-51, 2014.

[4] S. Das and A. Ghosh, "Solid Polymer Electrolyte Based on PVDF-HFP and Ionic Liquid Embedded with TiO 2 Nanoparticle for Electric Double Layer Capacitor ( EDLC) Application,” J. Electrochem. Soc., vol. 163, no. 13, pp. F1348-F1353, 2017.

[5] B. Evanko, S. W. Boettcher, S. J. Yoo, and G. D. Stucky, "Redox-Enhanced Electrochemical Capacitors :," ACS Energy Lett., vol. 2, pp. 2581-2590, 2017.

[6] S. Uppugalla, U. Male, and P. Srinivasan, "Electrochimica Acta Design and synthesis of heteroatoms doped carbon / polyaniline hybrid material for high performance electrode in supercapacitor application," Electrochim. Acta, vol. 146, pp. 242-248, 2014.

[7] H. J. Xie, B. Gélinas, and D. Rochefort, "Redox-active electrolyte supercapacitors using electroactive ionic liquids Electrochemistry Communications Redox-active electrolyte supercapacitors using electroactive ionic liquids," Electrochem. commun., vol. 66, pp. 42-45, 2017.

[8] D. You, Z. Yin, Y. Ahn, S. Lee, J. Yoo, and Y. S. Kim, "Redox-active ionic liquid electrolyte with multi energy storage mechanism for high energy density," RSC Adv., vol. 7, pp. 55702-55708, 2017.

[9] G. P. Pandey and S. A. Hashmi, "Ionic liquid 1-ethyl-3-methylimidazolium tetracyanoborate-based gel polymer electrolyte for electrochemical capacitors,” J. Mater. Chem. A, vol. 1, no. 10, p. 3372, 2013.

[10] J. Bai, H. Lu, Y. Cao, X. Li, and J. Wang, “A novel ionic liquid polymer electrolyte for quasi-solid state lithium air batteries," RSC Adv., vol. 7, no. 49, pp. 30603-30609, 2017.

[11] C. Liew, K. H. Ari, J. Kawamura, Y. Iwai, S. Ramesh, and A. K. Arof, "Effect of halide anions in ionic 
liquid added poly ( vinyl alcohol ) -based ion conductors for electrical double layer capacitors," J. Non. Cryst. Solids, vol. 458, pp. 97-106, 2017.

[12] A. Brandt, S. Pohlmann, A. Varzi, A. Balducci, and S. Passerini, "Ionic liquids in supercapacitors," vol. 38, no. July, pp. 554-559, 2013.

[13] G. P. Pandey, Y. Kumar, and S. A. Hashmi, "Ionic liquid incorporated polymer electrolytes for supercapacitor application," Indian J. Chem. - Sect. A Inorganic, Phys. Theor. Anal. Chem., vol. 49, no. 5-6, pp. 743-751, 2010.

[14] M. Moreno et al., "Ionic Liquid Electrolytes for Safer Lithium Batteries I . Investigation around Optimal Formulation,” J. Electrochem. Soc., vol. 164, no. 1, pp. A6026-A6031, 2017.

[15] M. Armand, F. Endres, D. R. MacFarlane, H. Ohno, and B. Scrosati, "Ionic-liquid materials for the electrochemical challenges of the future," Nat. Mater., vol. 8, no. 8, pp. 621-629, 2009.

[16] J. Chattoraj, D. Diddens, and A. Heuer, "Effects of ionic liquids on cation dynamics in amorphous polyethylene oxide electrolytes," J. Chem. Phys., vol. 140, no. 2, pp. 2-8, 2014.

[17] S. P. Ong, O. Andreussi, Y. Wu, N. Marzari, and G. Ceder, "Electrochemical windows of roomtemperature ionic liquids from molecular dynamics and density functional theory calculations," Chem. Mater., vol. 23, no. 11, pp. 2979-2986, 2011.

[18] B. A. Mei, O. Munteshari, J. Lau, B. Dunn, and L. Pilon, "Physical Interpretations of Nyquist Plots for EDLC Electrodes and Devices," J. Phys. Chem. C, vol. 122, no. 1, pp. 194-206, 2018.

[19] H. Yu et al., "A novel redox-mediated gel polymer electrolyte for high-performance supercapacitor," $J$. Power Sources, vol. 198, pp. 402-407, 2012.

[20] J. P. Tey, M. A. Careem, M. A. Yarmo, and A. K. Arof, "Durian shell-based activated carbon electrode for EDLCs," Ionics (Kiel)., vol. 22, no. 7, pp. 1209-1216, 2016.

[21] R. Ramya, R. Sivasubramanian, and M. V Sangaranarayanan, "Conducting polymers-based electrochemical supercapacitors - Progress and prospects," Electrochim. Acta, vol. 101, pp. 109-129, 2013.

[22] C. Zhong, Y. Deng, W. Hu, J. Qiao, L. Zhang, and J. Zhang, "A review of electrolyte materials and compositions for electrochemical supercapacitors," Chem. Soc. Rev., vol. 44, no. 21, pp. 7431-7920, 2015.

[23] N. Harankahawa, S. Weerasinghe, K. Vidanapathirana, and K. Perera, "Investigation of a Pseudo Capacitor with Polyacrylonitrile based Gel Polymer Electrolyte," J. Electrochem. Sci. Technol., vol. 8, no. 2, pp. 107-114, 2017.

[24] P. A. Basnayaka et al., "High Performance Asymmetric Supercapacitors Based on Dual Phosphorus ( P ) and Nitrogen ( N ) co-Doped Carbon and Graphene-Polyaniline Electrodes," J. Solid State Sci. Technol., vol. 6, no. 6, pp. 3168-3172, 2017. 
[25] G. P. Pandey, S. A. Hashmi, and Y. Kumar, "Performance Studies of Activated Charcoal Based Electrical Double Layer Capacitors with Ionic Liquid Gel Polymer Electrolytes,” Energy \& Fuels, vol. 24, no. 12, pp. 6644-6652, 2010.

[26] A. Rezqita, M. Sauer, A. Foelske, H. Kronberger, and A. Trifonova, "The effect of electrolyte additives on electrochemical performance of silicon/mesoporous carbon (Si/MC) for anode materials for lithiumion batteries," Electrochim. Acta, vol. 247, pp. 600-609, 2017.

[27] A. Gupta and S. K. Tripathi, "Effect of anionic size of PMMA Based Polymer Gel Electrolytes for Redox Capacitor,” pp. 3-5, 2013.

[28] M. Mastragostino, C. Arbizzani, and F. Soavi, "Polymer-based supercapacitors," vol. 98, pp. 812-815, 2001 .

[29] A. Jain and S. K. Tripathi, "Experimental studies on high-performance supercapacitor based on nanogel polymer electrolyte with treated activated charcoal," Ionics (Kiel)., vol. 19, pp. 549-557, 2013.

[30] K. Wang, H. Wu, Y. Meng, Y. Zhang, and Z. Wei, "Integrated energy storage and electrochromic function in one flexible device : an energy storage smart window," Electron. Suppl. Mater. Energy Environ. Sci., pp. 1-5, 2012.

[31] K. S. Ryu, K. M. Kim, N. Park, Y. J. Park, and S. H. Chang, "Symmetric redox supercapacitor with conducting polyaniline electrodes," vol. 103, pp. 305-309, 2002.

[32] S. Palaniappan, S. B. Sydulu, T. L. Prasanna, and P. Srinivas, "High-Temperature Oxidation of Aniline to Highly Ordered Polyaniline - Sulfate Salt with a Nanofiber Morphology and Its Use as Electrode Materials in Symmetric Supercapacitors,” J. Appl. Polym. Sci., vol. 120, pp. 780-788, 2011.

[33] F. Ataherian and N. Wu, "Long-Term Charge / Discharge Cycling Stability of MnO 2 Aqueous Supercapacitor under Positive Polarization,” J. Electrochem. Soc., vol. 158, no. 4, pp. A422-A427, 2011. 
Figures

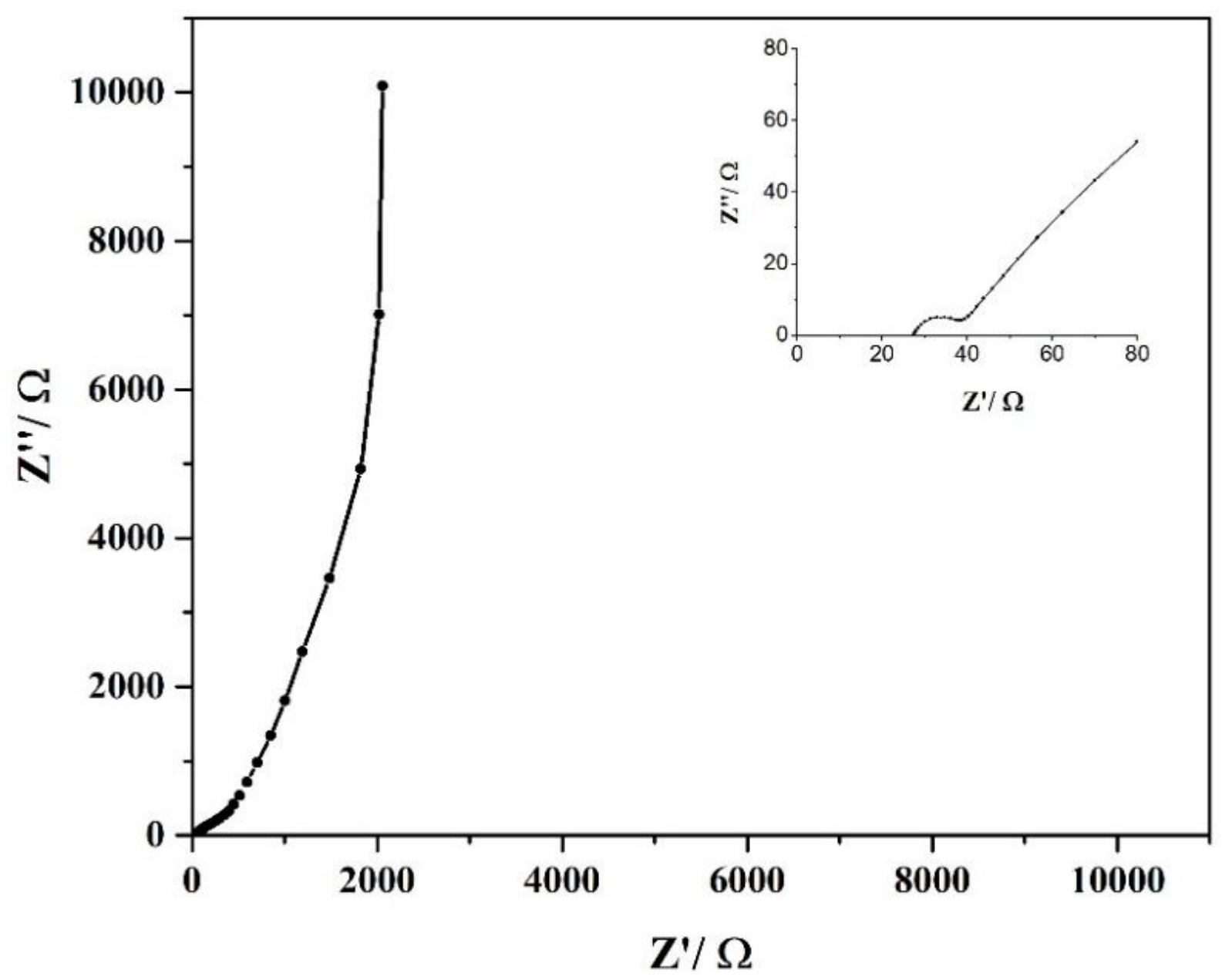

Figure 1

The Nyquist plot of the redox capacitor PPy: ZnTF/ 1E3MITF: ZnTF: PVdF-co-HFP/ PPy: ZnTF in the frequency range $0.001 \mathrm{~Hz}$ to $400 \mathrm{kHz}$ 

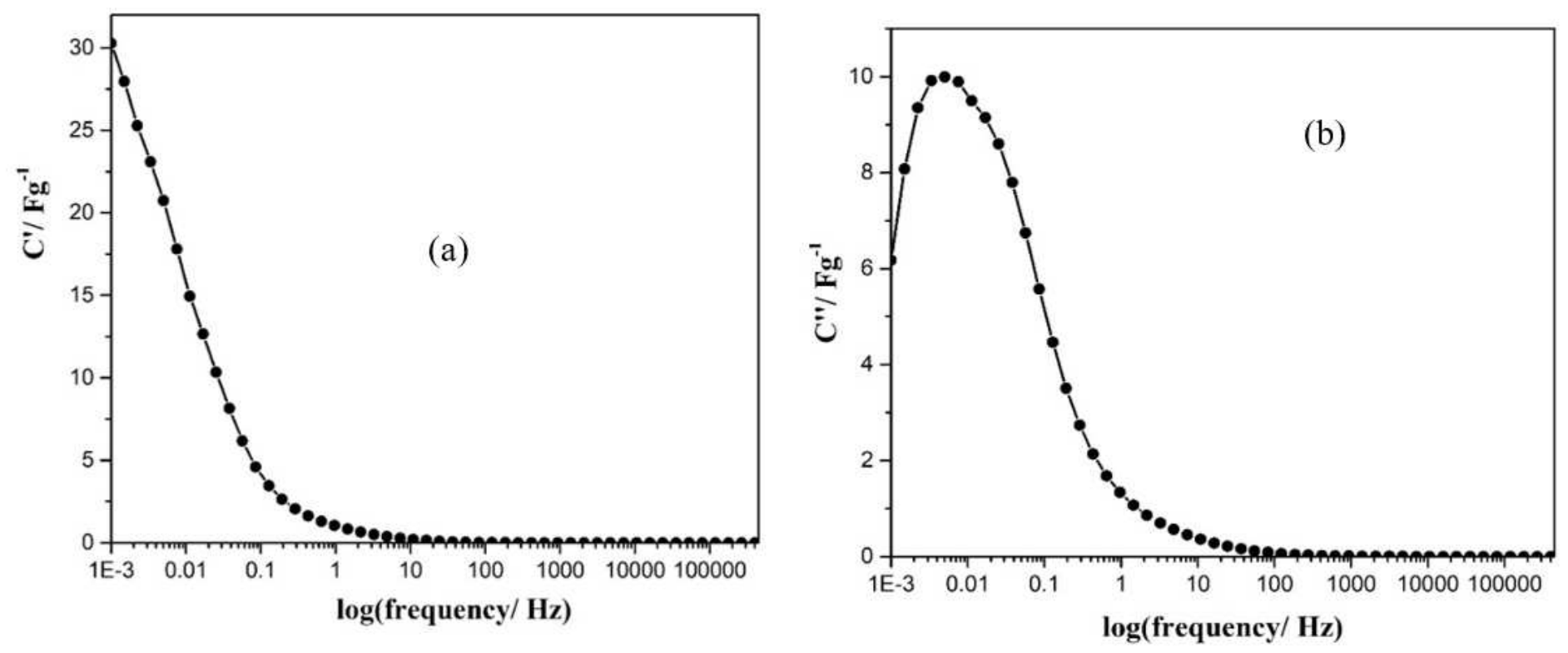

Figure 2

Bode plots of the redox capacitor PPy: ZnTF/ 1E3MITF: ZnTF: PVdF-co-HFP/ PPy: ZnTF in the frequency range $0.001 \mathrm{~Hz}$ to $400 \mathrm{kHz}$

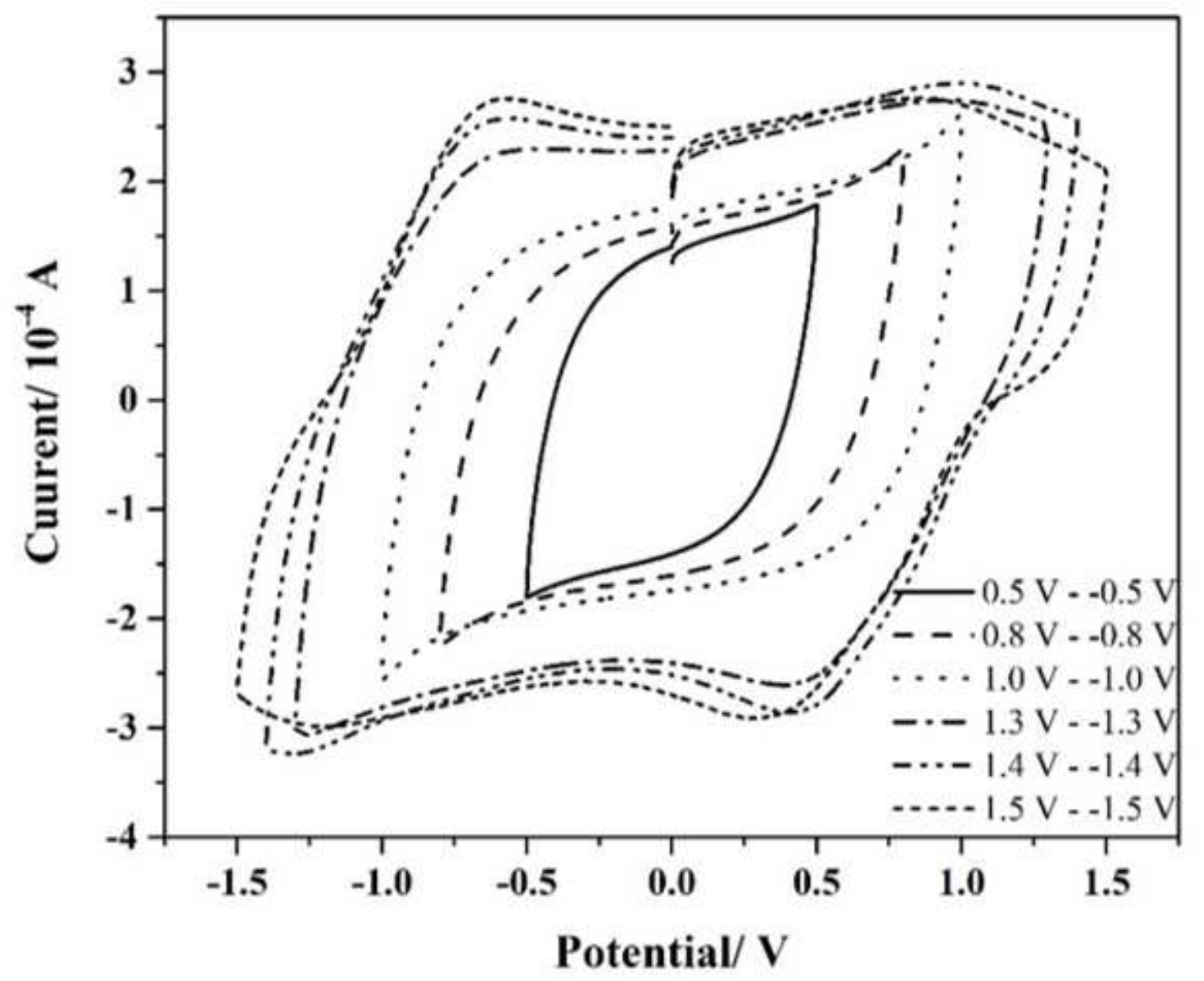


Figure 3

Cyclic voltammograms at different potential windows at the scan rate of $10 \mathrm{mVs}-1$ for the redox capacitor PPy : ZnTF/ PVdF-co-HFP : 1E3MITF : ZnTF/ PPy : ZnTF
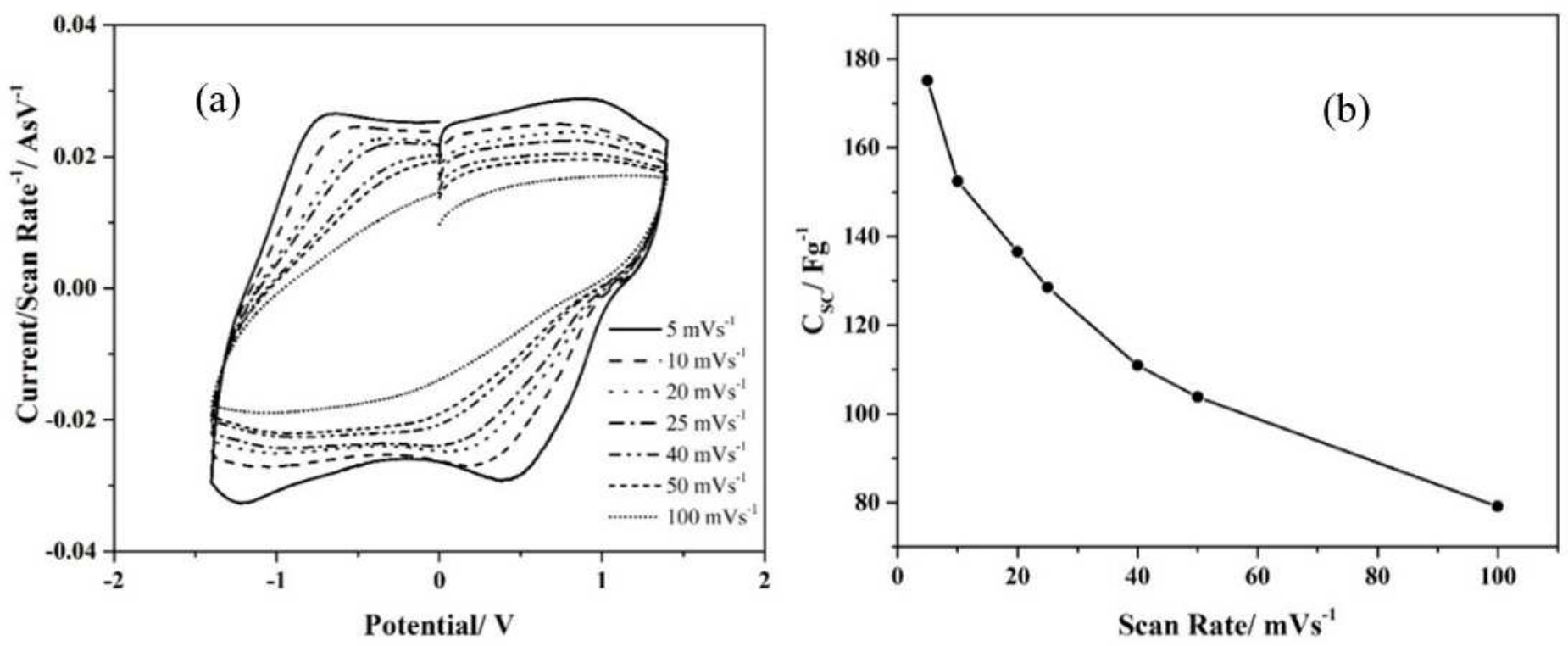

Figure 4

(a) Resulted cyclic voltammograms at different scan rates (b) corresponding CSC values of the cyclic voltammograms at the window from $-1.4 \mathrm{~V}$ to $1.4 \mathrm{~V}$ for the redox capacitor PPy : ZnTF/ PVdF-co-HFP : 1E3MITF : ZnTF/ PPy : ZnTF
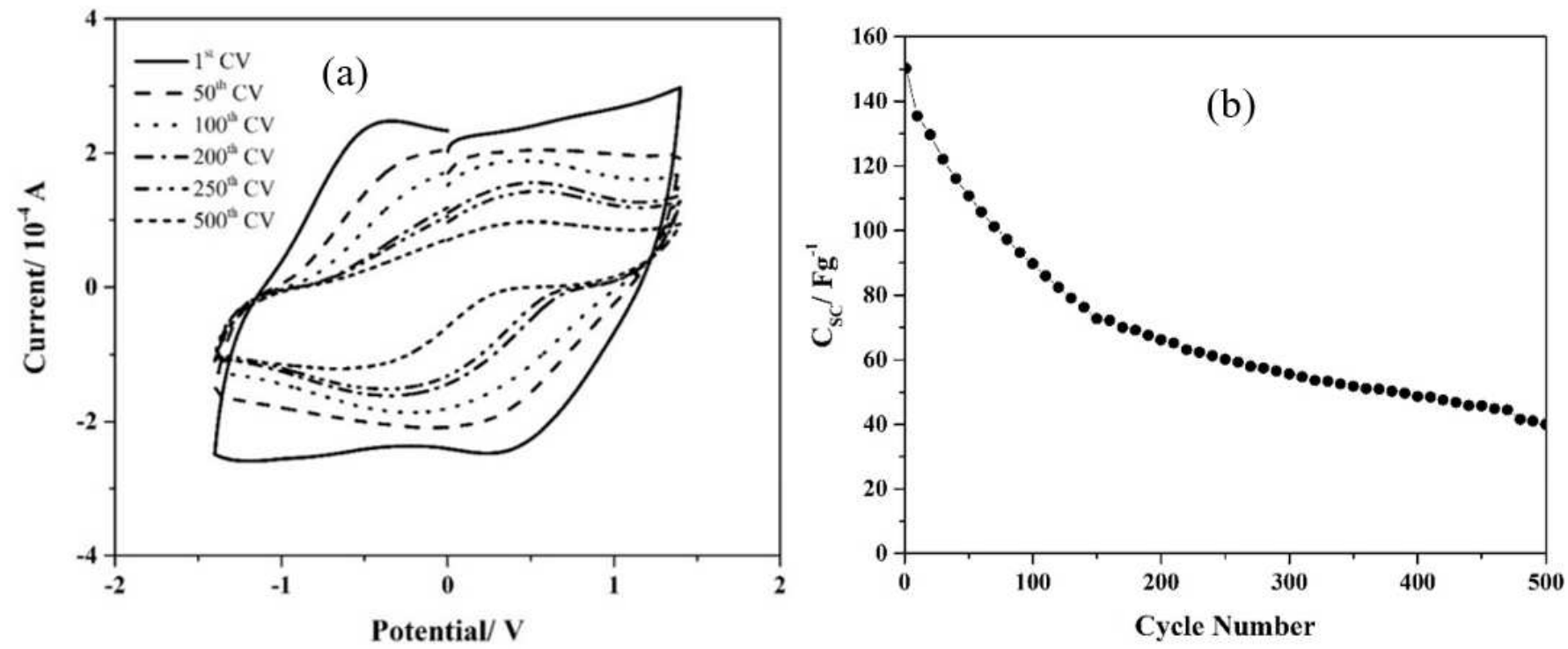

Figure 5

(a) First, 50th, 100th, 200th, 250th, and 500th cyclic voltammograms (b) Variation of CSC upon continuous cycling at the scan rate of $10 \mathrm{mVs}-1$ and within the potential from $-1.4 \mathrm{~V}$ to $1.4 \mathrm{~V}$ 

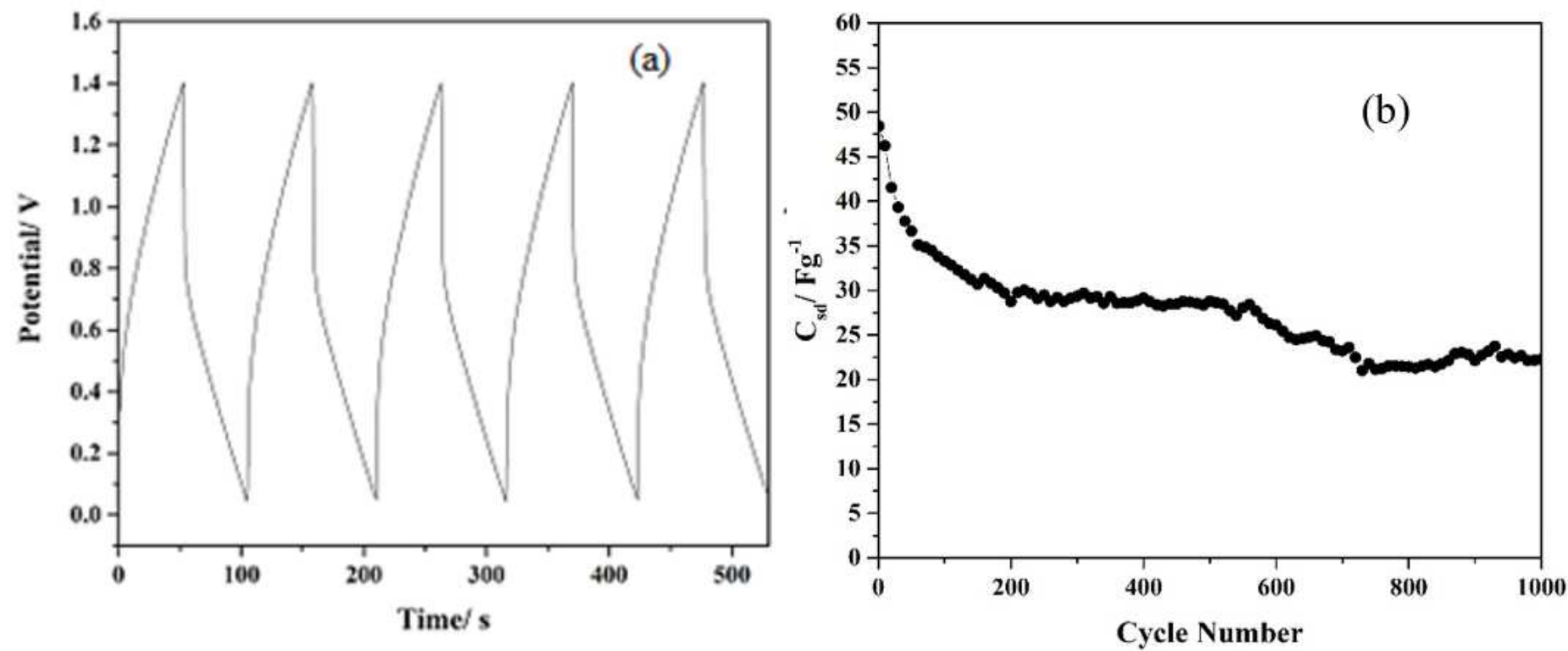

Figure 6

(a) GCD cycles (b) variation of Csd with the cycle number for the redox capacitor PPy : ZnTF/ PVdF-coHFP : 1E3MITF : ZnTF/ PPy : ZnTF at constant current of $230 \mu \mathrm{A}$ within the potential $0.1 \mathrm{~V}$ to $1.4 \mathrm{~V}$ 